\title{
Delinquency Prevention through Crime Conservation
}

\author{
Ahlam Mohammadi ${ }^{1} \&$ Zahra Abedinejad Mehrabadi $^{1}$ \\ ${ }^{1}$ Islamic Azad University, International Units of Khorramshahr, Khalije Fars, Iran \\ Correspondence: Ahlam Mohammadi, Islamic Azad University, International Units of Khorramshahr, Khalije \\ Fars, Iran. E-mail: Ahlammohamadi1984@gmail.com
}

Received: April 17, 2016 Accepted: June 11, 2016 Online Published: July 25, 2016

doi:10.5539/jpl.v9n7p35

URL: http://dx.doi.org/10.5539/jpl.v9n7p35

\begin{abstract}
Nowadays, the prevention of crime over the past are subjected to the judicial authorities seriously and criminal policy has adopted a set of measures to deal with criminal phenomenon that a part of the measures returns to situational prevention measures which seeks to limit the opportunities and situations causing offense and makes difficult to realize the criminal mind. Further, one of these strategies, protect and support the target of crime. In addition the community has not been achieved in take away of the mind and think of the people from crime and social prevention, perfectly. Therefore, we must think of the stockade after the realizing of the criminal act. Owing to one of the ways in which the transition from thought to action make difficult is strengthening the protection of crime targets so the aim of the choice of the current title is trying to realize to prevention from delinquency by protecting the target of crime. Moreover, research methodology is explanatory method using the library resources, the finding of the author of this study is that the organized protection of targets that are more vulnerable to crime will be an effective step towards restriction the crime. In conclusion this protection will be including outside the in-hand targets of criminals or exposed them in the public view, technical measures of protection of the homes and vehicles and other property, property marking, control of inputs and outputs, electronic protections such as video surveillance and protection from software data.
\end{abstract}

Keywords: crime targets, criminal policies, protection, conservation, conservative strengthening

\section{Introduction}

The term of protection and strengthening targets is used in one of the approaches related to situational crime prevention which aims to enhance the security of crime targets; so, in this way, committing crime would be more difficult for criminals and it will be more dangerous. What some situational prevention approaches, including changes in crime commitment environment, strengthening the position of the accused, electronic and non-electronic protection of targets and controlling criminals and other cases require is to develop new approaches of committing crime and new kinds of crime. In cases where there are unprotected targets, not only professional criminals prefer these kinds of targets on protected ones, but also non-professional and potential criminals encounter with such a simple circumstance of committing crime in the way that they are tempted to commit a crime.

Some researchers consider each part of the situational prevention plans as a controlling category in certain types of crimes. Among them, there is protection of targets and making difficult them in a relatively regular and permanent approach which results in increasing criminal attempt or threat of committing crime and decreasing its benefits and consequences; in this way, installing locks and security devices, transferring the targets at risk to safe locations, and controlling their availability will be achieved. When a criminal act is done barely or its occurrence becomes impossible, this category will be another goal achieved using this method (Moazami, 2000). In fact, it is said that all legal and legitimate equipment and tools should be used for preventing crime and reducing crime rates, including limiting criminal access to targets and crime objectives. In foundations of Islamic criminal policy, there is no advice about existence of criminal opportunities and circumstances; therefore, despite some, a field is provided to test individuals, but there is an emphasis on avoidance of committing crime and sin. Consequently, it is concluded that despite making efforts to make human soul and having an internal self-controlling potential, it is necessary to pay appropriate attention to external controlling (such as targets conservation and keeping them away from criminals). Criminals always try to overcome the barriers of committing crime, so it is necessary to make use of methods which increase the risks of committing crime and minimize the benefits resulted from it, in this way, committing crime will not be economical. 


\section{Definition of Prevention}

The word prevention literally means rebuff, arrest, intercept as well as precautions to prevent bad and unwanted events (Moein, 1980)

Applying criminal acts and plans in order to prevent re-committing crime by criminals or other people of the community is the first concept perceived at first glance regarding this term. Studies and findings in the field of criminal law imply that human societies make use of punishments mainly to deal with crimes (Najafi Abrandabadi, 2007)

Situational prevention is one of the methods of crime prevention which aims to prevent people from committing crimes through making changes in individual status or conditions of external environment such as place and time. There are different definitions of situational prevention that will be explained and analyzed according to the objectives and principles of crime prevention through targets conservation.

In the introduction part of his book titled Situational Crime Prevention published in 1992, Clarke states that situational prevention theory refers to a specific method, which aims not only to exalt society and its institutions but also to rely simply on reducing opportunities and circumstances of committing crime (Saffari, 2009). Another definition states that prevention through targets or situation-based conservation by mastering the environment and circumstances of committing crime aims to reduce crime rates through decreasing the attractiveness of targets and pre-criminal situation (Najafi Abrandabadi, 2008)

According to the definitions, prevention through targets' conservation involves two categories of plans and objectives: the first category refers to plans which seek to foreclose the possibility of committing criminal act or at least make it difficult such as making difficult access to targets or protecting potential victims which were emphasized more in first definition.

The second category which refers to plans and procedures aiming to mitigate criminal attractions and situational provocative factors seeks to prevent criminal final decision and its transition from thought to action. In this regard some examples are mentioned as follows: Hijab and hiding jewelries by women, not using doors made of glass or doors with parts of glass in stores in off hours especially during nights, installing cameras or electronic eyes and many other plans which reduce the attraction of targets or increase the risk of crime. Of course, in addition to making crime committing difficult and impossible, the plans of first category mitigate motives for committing a criminal act due to difficult access to targets or the accused one, rises in costs of committing crime and decreases in benefits resulted.

It should be emphasized that this research observes all activities aiming to achieve to the two mentioned goals. Therefore, in definition of situational prevention, both objectives including making criminal act difficult or impossible and preventing criminal temptation should be considered. (Mirkhalili, 2009)

In definition of objectives and situational prevention, today, researchers often consider these two objectives determining the scope and extent of situational prevention and they also point out that prevention through targets' protection aims to mitigate opportunities for committing criminal acts by "limiting access to targets" and "reducing attractions".

\section{Prevention Fundamentals of Protection of Crime Targets}

Many of the fundamental issues about man and his nature such as human determinism or freedom and especially in view of absolute negation of determinism and libertarianism among the Shia' scholars can be concerned as the most important and main context and fundamentals of situational prevention theory. (Keynia, 1994) Although, rejection of determinism in these teachings means denying God's complete intervention in human optional affairs, the relative accept of human determinism and freedom means that human is a creature which has the selection right; therefore, he makes different decisions against different situations and he changes his decisions in new situations. Consequently, person's decision for committing crime can be changed by changing situations and opportunities. Second, many factors of committing crimes including social and situational are out of the criminal's will; therefore, committing crime would not be possible in certain situations by limiting opportunities. Various theories have been proposed in different fields related to criminal, victim and crime discussing about human, human will or lack of it in his acts and behaviors and other relevant topics (Keynia, 1994). In an article about prevention through environmental design published by the Australian institute of criminology, Ronald Clark expresses the principles of situational prevention and issues such as opportunity and rational choice theory (Mirkhalili, 2009). 


\section{Goals of Protective Prevention in Criminal Law}

Delinquency is a very complex social phenomenon observed in different forms in different social environments. The realization of crime prevention is not an authorized and worthwhile category at any cost, but observance of some principles and standards is essential. Principles which not only guarantee the effectiveness of crime prevention, but eliminate its clear and hidden damages. These principles are considered as the basic framework of a model of crime prevention, it is always necessary to observe them in all the time and places and there should not be ignored or violated. Neglecting any of these principles will lead to the failure of attempts regarding crime prevention (Mirkhalili, 2009). As mentioned in definitions of situational prevention, this method has two major and main objectives. The first objective is about making committing crime difficult or impossible despite criminal intentions by using different techniques of situational prevention and the second objective considers prevention of criminal motives' escalation or prevention of creating immediate motives by reducing criminal attractions (Ghafuri Ghoravi, 1990)

\subsection{Making Committing Crime Difficult or Impossible}

The most important goal of situational prevention which dedicates most of methods and solutions to itself relates to making committing crime difficult or impossible despite criminal motivation. Strategies refer to changes in situations and opportunities such as input and output controlling, creating a defensible space, collecting tools and accessories related to committing crime such as gun and etc. These are of cases which aim to make impossible committing crime and prevent criminal committing it. Care and supervision on criminals and protection of victims are also mainly conducted with the mentioned objective.

In areas of situational prevention in Islamic criminal policy, in definition of situational prevention by Islamic scholars, it implies that concept and target of situational prevention is to disable the criminal from committing a crime. For example; prevention of crime and unlawful affair means to incapacitate the subject of committing crime, whether he himself willingly restrain committing crime or not. (Mir Khalili, 2009)

Therefore, one of the objectives of situational prevention plans including setting physical barriers between criminal and criminal targets or installing locks and doors made of iron, police monitoring and etc is to disable agent and potential criminal from committing crime, but it should be noted that the mentioned plans may sometimes be effective in dissuading criminal from committing crime.

This objective is inferred from some definitions such as a description by Gassin about this kind of prevention. He defines: situational prevention includes non-criminal actions aiming to "prevent criminal act and his thought" by changing certain circumstances which a series of similar crimes has occurred or may be committed in such situations. (Gassin, 2009)

\subsection{Prevention of the Development and Progression of Criminal Motives}

Some of prevention strategies and methods are exclusively used with the aim of dissuading criminals and preventing the development and progression of criminal motives. Raising the risk of identification and arrest of offenders, reducing tempting environmental attractions, installing hidden cameras and electronic eyes, having Hijab and avoiding make up by women outside the home and some examples like these belong to categories aiming to prevent the emergence and development of motivation and stop potential criminals from committing crime.

Therefore, situational prevention aims to prevent reaching a specific target or making an attack to victim by changing the previous situations of committing crimes, for example through support or protection of the victim or the potential crime targets by using the most effective means and making committing crime difficult and thus it is assumed that the criminal will disregard carrying out his thoughts in compared with those targets or the supported victim.

Theorists of situational prevention believe that the probability of committing a crime depends on how different elements of environment are perceived by potential criminal. Situational crime prevention can be compared with the operating concept in psychology meaning actuator control. They believe that the possibility of committing crime is strengthen or weaken based on the quality of setting stimuli in the environment; the stimuli can be changed by managing, designing or interfering in the environment.

Inspired by rational choice theory, Clarke claims that achieving to the ultimate goal of situational prevention requires some arrangements in which the cost of committing crime is more than its profit. According to this goal, situational prevention methods are classified in three categories:

Methods which increase attempts for committing a crime successfully. 
Techniques that making committing crime dangerous.

Means which reduce the attractiveness of the subject of crime. (Gassin, 2009)

Gassin considers the goal of situational prevention, including some activities which directly or indirectly "influence peoples' personality" in order to refrain from organizing their activities about criminal motivations. By changing previous situations of committing crime, for example, through support and protection of the victim or crime targets and examples like these by raising the risk of identifying and arresting the criminal and reducing criminal's desired pleasure, this method claims that criminal will disregard carrying out his thoughts in compared with the victim or targets in such circumstances and it is the aim of situational prevention. (Gassin, 2009)

The attractiveness of situational prevention activities depends extensively on their ability in offering realistic solutions and often simple and low-cost ways for certain types of crime in different ranges of particular situations. Of course, the success of these plans depends also on this category that to what extent potential criminals consider situational changes as a negative factor influencing the simplicity of the committing crime, risks and benefits and how much these conceptions influence their decisions in committing crime. (Mirkhalili, 2009)

\section{The Status and Scope of Protection of Targets in Crime Prevention}

\subsection{Physical Protection}

Some of prevention strategies and methods are exclusively used with the aim of dissuading criminals and preventing the development and progression of criminal motives. Raising the risk of identification and arrest of offenders, reducing tempting environmental attractions, installing hidden cameras and electronic eyes, having Hijab and avoiding make up by women outside the home and some examples like these belong to categories aiming to prevent the emergence and development of motivation and stop potential criminals from committing crime.

Therefore, situational prevention aims to prevent reaching a specific target or making an attack to victim by changing the previous situations of committing crimes, for example through support or protection of the victim or the potential crime targets by using the most effective means and making committing crime difficult and thus it is assumed that the criminal will disregard carrying out his thoughts in compared with those targets or the supported victim.

In addition to encouraging individual to commit a crime and reducing its risks and motivating criminals, Exposure to crime targets is one of the factors which causes that criminals commit crimes and reach to their targets without any hindrance. Targets protection reduces expected gains resulted from committing crimes and make difficult or impossible committing crime. Some examples are mentioned as follows:

\subsubsection{Unavailability of Targets by Criminals}

Through making targets unavailable to criminals and designing the environment in the way that opportunities for committing crime minimize, committing some crimes can be simply prevented. For example, transferring devices which need coin to work and be effective in public places to situations that they can be preserved, can protect them against breaking and destruction. Extensive use of check, credit cards and other forms of plastic money instead of paper one, reduces the opportunities for committing crimes such as robbery from machines carrying money or theft of telephone kiosks. Other examples are prevention of theft of funds paid by passengers on trains and buses through vast use of tickets paid previously. (Mirkhalili, 2009)

In addition to the mentioned examples, many other instances of targets protection which are effective in prevention are presented. What is important in this discussion is that centers pertaining to the police and custodians of discovery and prosecution of crimes with respect to the objectives and crime targets can timely organize and implement useful plans against committing crimes; in this case an effective action has been performed in prevention of committing crimes. Also, targets of criminals should be considered in statistical analysis of crimes committed in different areas and they should be notified to relevant authorities. (Hatefi Ardakani, 2002)

\subsubsection{Technical Strategies for Protection of Crime Targets}

Every crime considers its own certain targets as the objective of crimes. for example, human is the subject of crimes such as murder and intentional harm and property or financial documents are the targets of crimes such as theft, fraud and defalcation. Targets are divided to two main groups: material targets like the above mentioned example and intellectual and spiritual targets such as dignity, personality and honor. There is no doubt or objection about situational prevention in material targets. But the occurrence of intellectual targets cannot be 
predicted to identify opportunities and situations and change them; because it seems difficult that how immaterial targets can be considered as the subject of situational prevention activities. Experience has shown that target protection has a significant impact on lowering statistics related to crimes. When the use of the steering wheel lock became compulsory for all new and old automobiles in Federal Republic of Germany, car theft was dramatically reduced. Strategies related to situational prevention can be organized appropriately through studying different styles of committing crime such as theft. Methods such as cutting lock, destroying door, broking the glass of window and door, piercing the wall, making a spare key, cutting fences, removing the lock, entering through the roof or by rope, using a ladder or by the help of another person for holding criminal and pushing him to enter the situation, entering through climbing a tree or electricity pole, entering through ventilation holes, backyard, air channel, skylight, shops door, burrowing and etc are used by thieves which should be noted. (Hatefi Ardakani, 2002)

This technical approach reducing opportunities for committing crimes is in fact increase of physical security of targets through the use of locks, resistant and unbreakable materials, preventive and warning devices, putting vulnerable objects behind the fence or in a safe, and etc. some statistics show that some cases of destruction such as destroying public telephone kiosks and stealing money and cases of theft from stores and commercial buildings have been relatively reduced through switching coin boxes made of steel or aluminum and using alarm systems. (Mirkhalili, 2009)

\subsubsection{Marking the Property}

Fixed marking of property such as automobile, bicycle and valuable tools of the home lessens their value for criminals through making easier their identification; therefore, they are used and sold barely. Names or identification numbers can be written by special tool or with invisible ink on property. The use of capsules of paint in night safe and ATM is a new type of highly effective method. In the event of theft, paint capsules start to work and banknotes become worthless. However, only marking the property has not enough impact on this category that the property is returned or it is prevented to resell them in the case of theft. (Hatefi Ardakani, 2002)

The owner can stop the buying and selling stolen property through giving identity to automobiles by invisible numbers. Swiss watchmaking factories give identity to their products by writing a certain number on them and in this way, they control buying and selling stolen watches. The use of coded controls for cars, their recorders, computer and etc should be implemented in such a way that working with them without it is practically unusable.

\subsubsection{Controlling Inputs and Outputs}

The owner control on big shops is less than his control on small shops; therefore, the possibility of theft in big stores is more than others. People may be easily tempted to steal, so sometimes when people coming out, they control others' bags. A better method is to install magnetic gates; in the case of theft, alarming is heard. However, despite these plans, sometimes robbing from stores continues. In western theories, a certain amount of theft is due to appropriate decoration (because appropriate decoration is tempting.) (Mirkhalili, 2009)

Strategies such as controlling inputs and outputs, formal care, care by staff and natural supervision can increase the possibility of arresting criminals. In this way, the crimes risks will be heavier in compared with their advantages.

The possibility of observing relevant authorities in hours and situations which the committing crimes are likely more; installing automatic output and input doors to reduce the possibility of non-presentation of a ticket; equip relevant staff or police with radio systems to guide them to the place of event or to request help (also warning buttons); presenting travelling carts to reduce fraud in tickets are some examples which should be noted. Installing and advertising closed circuit television, despite its costs, is only justified in the case that it helps to other functions not relating to crimes such as monitoring and regulating the movement of passengers and controlling crowding.

\subsection{Electronic Protection of Crime Targets}

The use of new technology and advanced developments in electronic is inevitable in the category of situational prevention of committing crime. As criminals change increasingly their methods of committing crime and use new ways, the knowledge of situational prevention should not be left behind. It should identify the possibility of committing crimes and misuses much more than them and predict the blocking ways of committing crimes. The proliferation of electronic facilities and procedures at the stores which the buyer is not faced with the seller leads in reducing the possibility of theft. Technology dynamics are shown in three parts: (Jalali Farahani, 2005)

1) Warning systems to discover or use of radiation in finding drugs, explosive materials and etc. 
2) Systems of television surveillance, monitoring and hidden cameras, and the protection and control center.

3) Systems of controlling inputs (identification) through magnetic cards, alarming cards, cameras, skylights, electronic eyes, making with electronic code, mirror, reading laser codes for entering and exiting and etc.

\subsubsection{Video Control}

Security and quality of living in a place depend on the perception and image of the residents living near that place. If people have a bad image of that space, the possibility of committing crime will be more there. This part is in close relation with broken windows. It means that a non-repaired and broken window is a sign of this subject that no one is concerned. In this way, breaking more windows has no costs or when a region is clean and writings on the walls were removed quickly and damages are repaired very soon, this impression is created that this place has owner.

According to the relatively limited research done in this area, the use of video door phone may help to prevention of committing crime by some non-native criminals especially if accompanied by television systems. It would be more effective to take control of underground car parks through the use of various technical means and methods. (Mirkhalili, 2009) In the Uk, some researchers evaluate the impacts of use of closed circuit television on ordinary theft and stealing by violence in four underground stations in London; they concluded that when these methods are combined with police certain patrols, the amount robberies lessens according to the assessment performed before and after these plans. (Boer, 2003)

\subsubsection{Protection of Software Data}

In general, today, what is known as software or computer crimes is divided to two groups: the first group are crimes which there are crimes like them in the physical world and the Internet environment facilitates committing crimes without any changes in criminal elements through opportunities given criminals. Crimes committed in this area are extensive and cover various crimes from ones against national and even international security such as terrorist acts to crimes committed against people and property. Some examples are disturbing public opinions, insulting, defaming, unauthorized disclosure of business secrets and etc through Internet networks. But, another range of cyber-crimes is related to abuses done in this environment which committing them is not feasible in physical space. Crimes such as unauthorized access to data or systems or scattering destructive programs such as viruses are not committed except in cyberspace; therefore, they are called absolute Internet crimes. (Jalali Farahani, 2005)

It is said that abuses in these systems are limited in terms of type and amount. Of course, it is derived from confined functionality of these systems. Major unauthorized actions are related to disturbing functions of these systems and consequently data destruction. Therefore, plans adopted to deal with them have more security approach. For example, seven elements are determined to preserve the security of electronic data processors which are as follows: administrative and organizational security, personnel security, electronic security, software and hardware security, operational security and precautionary planning. (Dazyani, 2004) Generally, plans related to situational prevention of cyber-crimes can be studied in four groups:

\section{A: Plans which restrict or prevent access}

These kinds of plans are among the most important strategies related to situational prevention of cyber-crimes which their early instances were used for prevention of committing crimes. In this method, it is tried to prevent entering or sending some illegal or unauthorized data through installing certain programs and systems on groups which have access to networks, including personal computers, routers, systems presenting network services, and most importantly creators of international contact points. (Mirkhalili, 2009) These systems and programs are mainly in the forms of firewalls and proxies. These tools contain a list of authorized and unauthorized subjects and act according to the adaptation process. Some of them act like filters and unilateral firewalls, it means that they prevent only entering unauthorized inputs, but some of them act reciprocally and protect outputs in addition to inputs. (Mirkhalili, 2009)

\section{B. Controlling plans}

Network controlling is considered important factor as a preventive act. This action is applied in two technical and human forms. In technical case, some tools or programs are installed on the system and all network activities of people, even strokes on the keyboards or areas in which have been clicked by the mouse are preserved. Then the agent can review these records to prosecute illegal actions. In fact, supervision and control of applications lead in this category that their motive for committing crime is not sanctioned, provided that the user is aware that his activities are monitored. Because, as it is known, hidden controlling is used only for gathering evidence against the accused and has no preventive effect. Now, many of spaces related to network connections certainly 
those welcomed by the young can be controlled technically and lively. But the most important advantage of this action in compared with other restrictive or preventive activities is to not to make some problems in users activities in addition to having preventive effects. It is related to important legal problems and interfere in personal affairs of people which was mentioned previously. (Hajidehabadi, 2004)

\section{C: Plans related to license issuing}

Here, it is tried to prevent entering unknown or unreliable persons based on certain standards. A simple example is use of password which has preserved its place in the past and now. Thus, only those have the right to use a system or site who have received password after passing the processes of identification and acquiring the necessary credentials. This authorization may be given to an individual according to gender, nationality, religion or specific thought trends. Nowadays, many improvements have been done in this area. For example, several new and effective methods are used for further promotion of security and minimizing the error rate. (Mirkhalili, 2009)

It seems that this method has no fundamental objections in compared with two other ones. Of course, it has some deficiencies too which are mentioned as follows: first, it is not applicable in all areas of Internet environment and its use is very limited. Second, of course, this category is true about other preventive tools, it relates to the immediate progress of technologies available on the Internet space. A system may enjoys an acceptable safety through having tools related to license issuing, but it seems no specialist can guarantee this safety until a certain time, because, this technology is experienced by thousands people in the world and its weaknesses are discovered very soon.

\section{Tools related to making anonymous and coding}

These two actions differ somewhat in terms of performance, but as they have a same goal, here are examined together. As these terms imply, these tools hide the true nature of a concept or make it incomprehensible. Therefore, there is an opportunity to engage in network activities safely. This is especially useful for women or children or generally those who are vulnerable. Because, they can continue their activities in Internet environment without being identified by cyber-criminals. But encryption tools are used for communications content. Here, the original text is encrypted based on certain codes and the receiver decrypts it by the keys which have. Unfortunately, there are a variety of tools in cyberspace in order to have access to peoples' communication. Applying encryption programs can reduce the risk of such attacks.

However, it should be remembered that there is also the possibility of using these tools for criminals. They reduce the possibility of making known their identity through hiding it or encrypting the content of criminal communications. Therefore, in compared with three mentioned strategies, this option has this weakness that although, it removes some opportunities for committing crime, it provides a secure area for committing other kinds of crimes too. (Jalali Farahani, 2005)

\section{Conclusion}

This study investigated various topics and it was concluded that despite the objections raised, situational prevention methods are complete and comprehensive and it merely does not relate to limited strategies for prevention of committing some crimes or certain criminals. Of course, it should be noted that most of methods suggested are common among all criminals in social or criminal prevention, while situational prevention strategies are of more extensive diversity and usually a special and unique strategy is recommended for every category of crimes; for example, protection of targets or marking property are practical in financial crimes, especially theft, but training victims and controlling crime tools are more effective in crimes against physical integrity of people. Due to the diversity of situational prevention strategies, as well as with respect to its main objectives including making committing crime difficult or impossible and reducing criminal attractions, criticism about this method and its exclusivity regarding unintentional crime prevention or some targets were raised and answered. It was concluded that the strategies of this method of prevention have appropriate sufficiency when organizing and administering in compared with all kinds of crimes, criminals and targets. Although, human was appealing to protective plans in order to protect himself and his property throughout the history, today, an organized protection of targets which are the most vulnerable would be an effective step towards removing crime dilemmas. This protection would be performed through making targets unavailable to criminals and putting them on public display, technical plans related to protection of homes, vehicles and other property, marking property, controlling outputs and inputs, electronic protection such as video and software data preservation.

\section{References}

Boer, A., \& Rover, E. (2003). Violence and Urban Insecurity. Tehran, Majd Publications. 
Dazyani, M. (2004). An Introduction to the Nature and Theoretical Classification of Computer Crime, Informatics Newsletter, No. 87

Fouri Ghoravi, H. (1990). Criminal Motivation. Tehran, Javidan Publications.

Gassin, R. (1991). An Introduction to Criminology, Translated by Keynia, M. Tehran Publicatiobs, Majd.

Gassin, R. (n.d.). Relations between Situational Prevention and Crime Control, Translated by Najafi Abrandabadi, A. Journal of Legal Studies, No. 24

Hajideh Abadi, A. (2001). Criminology, Encyclopedia of Imam Ali (Vol. 5). Tehran, Publishing and Printing Organization of Ministry of Culture and Islamic Guidance.

Hajideh Abadi, M. (1999). Crime Prevention, Encyclopedia of Imam Ali (Vol. 5). Tehran, Publishing and Printing Organization of Ministry of Culture and Islamic Guidance.

Hajideh Abadi, M. (2004), Enjoining Good and Forbidding Wrong and Criminal Policy. Journal of Law and Jurisprudence.

Hashem Begi, H., \& Najafi Abrandabadi, A. (1998). Encyclopedia of Criminology. Shahid Beheshti University Press.

Hatefani Ardakani, H. (2002). Issues of Financial and Economic Crimes of Theft, Articles of First National Conference on Social Problems in Iran, 6th volume, Agah Publications.

Jalali Farahani, A. (2005), Situational Prevention of Cyber Crime in the Light of Human Rights. Journal of Law and Jurisprudence, (6).

Keynia, M. (1994). Criminology (Vol. 1). Tehran University Press.

Mirkhalili, M. (2009). Situational Prevention, with a View to Islamic Criminal Politics. Thought and Culture Research Publications.

Moein, M. (1981). Persian Encyclopedia. Tehran, Amirkabir Publications.

Najafi Abrandabadi, A. (n.d.). Delinquency and Local Police. Journal of Legal Studies, Shahid Beheshti University's Faculty of Law, No. 19-20.

\section{Copyrights}

Copyright for this article is retained by the author(s), with first publication rights granted to the journal.

This is an open-access article distributed under the terms and conditions of the Creative Commons Attribution license (http://creativecommons.org/licenses/by/4.0/). 